\title{
Clustering K-Means Kinerja Assistant Sales Representative pada PT Pupuk Kujang Cikampek, Departemen Pemasaran dan Penjualan Ritel
}

\author{
*Adi Kurniawan" ${ }^{1}$, Ultach Enri' ${ }^{2)}$ \\ ${ }^{1,2)}$ Teknik Informatika, Fakultas Ilmu Komputer, Universitas Singaperbangsa Karawang \\ Correspondence author: adi.kurniawan17035@ student.unsika.ac.id \\ DOI: https://doi.org/10.37012/jtik.v7i2.546
}

\begin{abstract}
Abstrak
Perseroan Terbatas (PT) Pupuk Kujang merupakan salah satu anak perusahaan dari BUMN di indonesia yaitu PT Pupuk Indonesia Holding Company PT Pupuk Kujang merupakan perusahaan besar yang bergerak di bidang produksi, perdagangan, pemberian jasa, angkutan, dan ekpedisi.PT Pupuk Kujang memiliki struktur organisasi yaitu Departemen Pemasaran dan Penjualan Ritel. Assistant Sales Representative (ASR) merupakan jabatan bagi seseorang yang bekerja di PT Pupuk Kujang Cikampek, Departemen Pemasaran dan Penjualan ritel. Seringkali beberapa ASR tidak mencapai target dalam melakukan kegiatan, hal ini dapat merugikan perusahaan dikarenakan tingkat kinerja dari para ASR terdapat kekurangan sehingga tugas pokok Departemen Pemasaran dan Penjualan Ritel tidak tercapai dengan baik. Pada penelitian ini akan dilakukan pengelompokan dengan 3 klaster yaitu produktif, menengah produktif dan kurang produktif dengan metode clustering teknik algoritma K-Means. Hasil dari penelitian ini didapatkan sebanyak 6 ASR masuk ke dalam kelompok kurang produktif, 22 ASR masuk kedalam kelompok menengah produktif dan 8 ASR masuk kedalam kelompok produktif dengan adanya penelitian ini dapat dilakukan evaluasi kinerja kepada kelompok yang kurang produktif sehingga pencapaian target kegiatan ASR pada PT Pupuk Kujang Cikampek, Departemen Pemasaran dan Penjualan Ritel menjadi lebih mudah dan efisien dalam mengatur strategi dalam mengevaluasi kinerja ASR.
\end{abstract}

Kata Kunci: Data Mining, K-Means, Assistant Sales Representative, Pupuk Kujang Cikampek

\begin{abstract}
Abstrak
Limited Liability Company (PT) Pupuk Kujang is one of the subsidiaries of BUMN in Indonesia, namely PT Pupuk Indonesia Holding Company PT Pupuk Kujang is a large company engaged in production, trade, service provision, transportation, and expedition. PT Pupuk Kujang has an organizational structure. namely the Department of Marketing and Retail Sales. Assistant Sales Representative (ASR) is a position for someone who works at PT Pupuk Kujang Cikampek, Department of Marketing and Retail Sales. Often some ASRs do not reach the target in carrying out activities, this can be detrimental to the company because the level of performance of the ASRs is deficient so that the main tasks of the Marketing and Retail Sales Department are not well accomplished. This research will be grouped into 3 clusters, namely productive, medium productive and less productive with the K-Means algorithm clustering method. The results of this study found that 6 ASRs were included in the underproductive group, 22 ASRs were included in the productive middle group and 8 ASRs were included in the productive group. With this research, performance evaluation of the less productive groups could be carried out so that the achievement of ASR activities targets at PT Pupuk Kujang. Cikampek, the Department of Marketing and Retail Sales, it is easier and more efficient to set strategies in evaluating ASR performance.
\end{abstract}

Keyword: Data Mining, K-Means, Assistant Sales Representative, Pupuk Kujang Cikampek 


\section{PENDAHULUAN}

Perseroan Terbatas (PT) Pupuk Kujang merupakan salah satu anak perusahaan dari BUMN di indonesia yaitu PT Pupuk Indonesia Holding Company PT Pupuk Kujang merupakan perusahaan besar yang bergerak di bidang produksi, perdagangan, pemberian jasa, angkutan, dan ekspedisi.

PT Pupuk Kujang memiliki struktur organisasi yaitu Departemen Pemasaran dan Penjualan Ritel. Departemen Pemasaran dan Penjualan Retail memiliki tugas pokok yaitu merencanakan fungsi strategi, analisa, pemasaran, market intelligence dan penjualan seluruh produk retail Perusahaan. Tugas pokok tersebut tentunya dilakukan Departemen Pemasaran dan Penjualan Retail khususnya Assistant sales representative untuk menyiapkan strategi serta memberikan pelayanan terbaik dalam menjual produk pupuk.

Assistant Sales Representative (ASR) merupakan jabatan bagi seseorang yang bekerja di PT Pupuk Kujang Cikampek, Departemen Pemasaran dan Penjualan ritel. Tugas pokok dari para ASR tersebut berjalan dengan seiringnya pekerjaan mereka dalam melakukan kegiatan, antara lain melakukan kunjungan petani, kunjungan dinas, kunjungan kios, kunjungan kantor, serta melakukan kegiatan marketing activity.

Masalah pada penelitian ini adalah seringkali beberapa ASR tidak mencapai target dalam melakukan kegiatan, hal ini dapat merugikan perusahaan dikarenakan tingkat kinerja dari para ASR terdapat kekurangan sehingga tugas pokok Departemen Pemasaran dan Penjualan Ritel tidak tercapai dengan baik, hal ini dibuktikan dengan adanya data pencapaian target di februari 2021 seperti pada gambar 1.

\section{Capaian Kegiatan ASR}

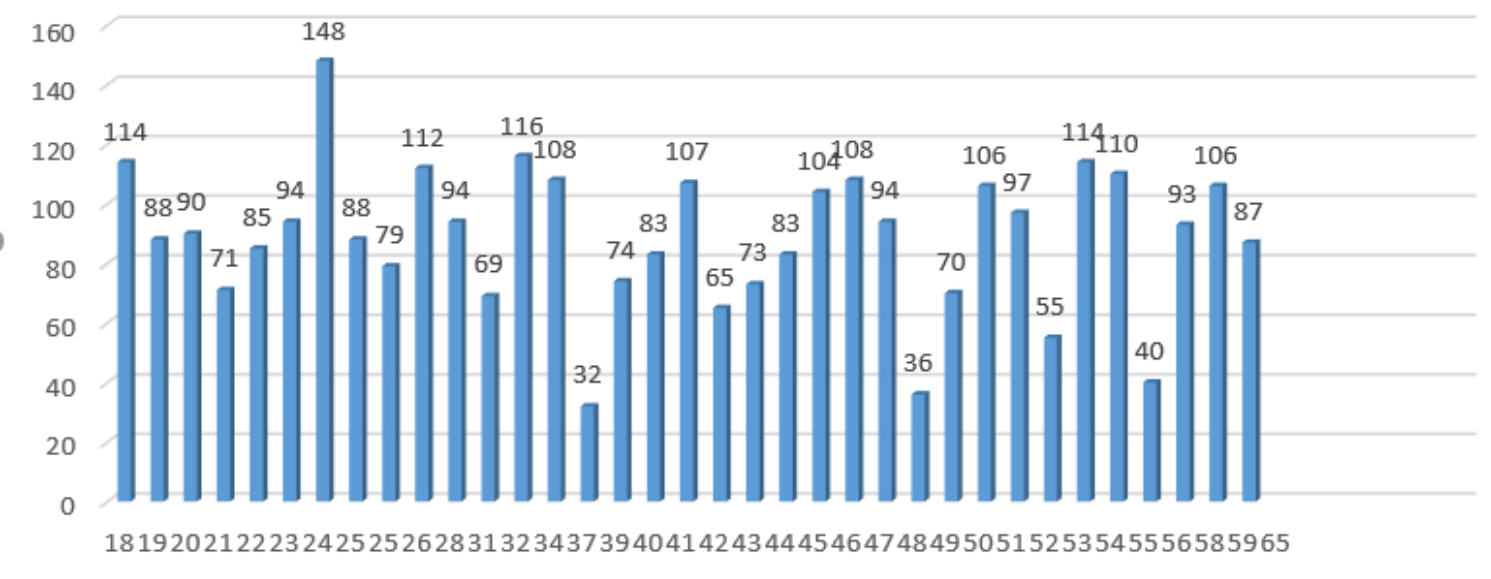

Gambar 1 : Grafik Capaian Kegiatan ASR 
Banyaknya kegiatan ASR di lapangan yang sudah ditetapkan oleh Departemen Pemansaran dan Penjualan Ritel yaitu minimal 110 kegiatan yang mencakup kegiatan kunjungan petani, kunjungan dinas, kunjungan kios, kunjungan kantor dan marketing activity. Pada gambar 1 terlihat sebanyak 30 ASR belum memenuhi capaian dalam melakukan kegiatan di lapangan. Grafik pada gambar 1 didapatkan dari data kegiatan ASR di bulan februari 2021.

Salah satu solusinya adalah dengan mencari pengetahuan menggunakan data mining, pengetahuan yang dihasilkan nantinya diperoleh dengan cara mengekstraksi data dan mengenali pola yang penting atau menarik dari data yang yang terdapat pada database (Vulandari, 2017). Penggunaan data mining pada penelitian ini adalah dengan cara mengelompokan (clustering) dimana metode clustering ini akan membagi data ke dalam grup-grup yang mempunyai suatu obyek dengan karakteristik yang sama sehingga masing masing grup memiliki sesuatu persamaan yang esensial (Bahauddin et al, 2021). Teknik yang akan digunakan dalam penelitian ini yaitu algoritma $K$-Means yang digunakan membagi-bagikan data ke dalam beberaa kelompok (grup atau cluster atau segmen) yang sesuai dengan yang diinginkan (Marpaung \& Siahaan, 2021), dimana akan dilakukan pembagian kelompok ASR menjadi 3 kelompok yaitu produktif, menengah produktif dan kurang produktif. Pertimbangan kriteria diantaranya ID ASR, jumlah hari kegiatan, jumlah kegiatan dan jenis kelamin yang nantinya hasil dari pengelompokan ini akan dilakukan evaluasi dan dapat diberikan suatu pelatihan agar kedepannya menjadi lebih baik.

Penggunaan Algoritma $K$-means pada penelitian sebelumnya didapatkan 2 hingga 4 kelompok yang digunakan sebagai pertimbangan dalam membedakan antara pegawai honorer satu dengan yang lain dan mampu memberikan informasi kepada Dinas Perumahan dan Pertanahan Provinsi Bengkulu, yaitu siapa saja yang layak untuk diberikan kontrak baru dari hasil pengelompokan data penilaian kinerja pegawai honorer dengan menggunakan algoritma K-Means (Aliense et al, 2021). Penelitian sebelumnya juga dari data yang didapatkan mampu dihasilkan pengelompokan indikator budaya organisasi yang dikelompokan berdasarkan 3 kelompok yaitu Constructive Cluster, Passive or Defensive Cluster dan Aggressive Cluster (Oktifiani et al, 2019). Penelitian Sebelumnya juga dilakukan untuk menyeleksi karyawan yang berpotensi dikeluarkan dari perusahaan. Hasil yang didapatkan pada penelitian Metode K-Means Clustering mampu melakukan pengelompokan dan prediksi karyawan yang berpotensi di PHK ke dalam 2 kelompok, yaitu memiliki potensi PHK dan tidak memiliki potensi PHK (Purba et al, 2019). 
Seperti pada penelitian sebelumnya, maka penelitian yang akan dilakukan oleh peneliti adalah ” Clustering K-Means Untuk Evaluasi Kinerja Assistant Sales Representative pada PT Pupuk Kujang Cikampek, Departemen Pemasaran dan Penjualan Ritel.”. PT Pupuk Kujang Cikampek, Departemen Pemasaran dan Penjualan Ritel dapat menyelesaikan permasalahan target yang akan dicapai oleh para ASR menjadi lebih baik lagi kedepannya dengan bantuan data mining metode clustering algoritma K-Means.

\section{METODE PELAKSANAAN}

Penggunaan data mining dalam penelitian ini adalah data akan dilakukan proses ekstraksi dimana sebelumnya tidak diketahui, bersifat implisit, dan dianggap tidak berguna) yang selanjutnya akan didapatkan sebuah informasi atau pengetahuan atau pola yang berguna untuk pelaporan atau pemantauan, penelitian ini masuk kedalam strategi deskriptif yang berfokus pada peringkasan dan konversi data menjadi informasi yang bermakna (Suntoro, 2019).

Agar mudah dipahami tahapan penelitian ini dijabarkan menggunakan flowchart, yang selanjutnya akan dijadikan apnduan dalam proses penelitian ini. Berikut adalah flowchart penelitian seperti pada gambar 2 .

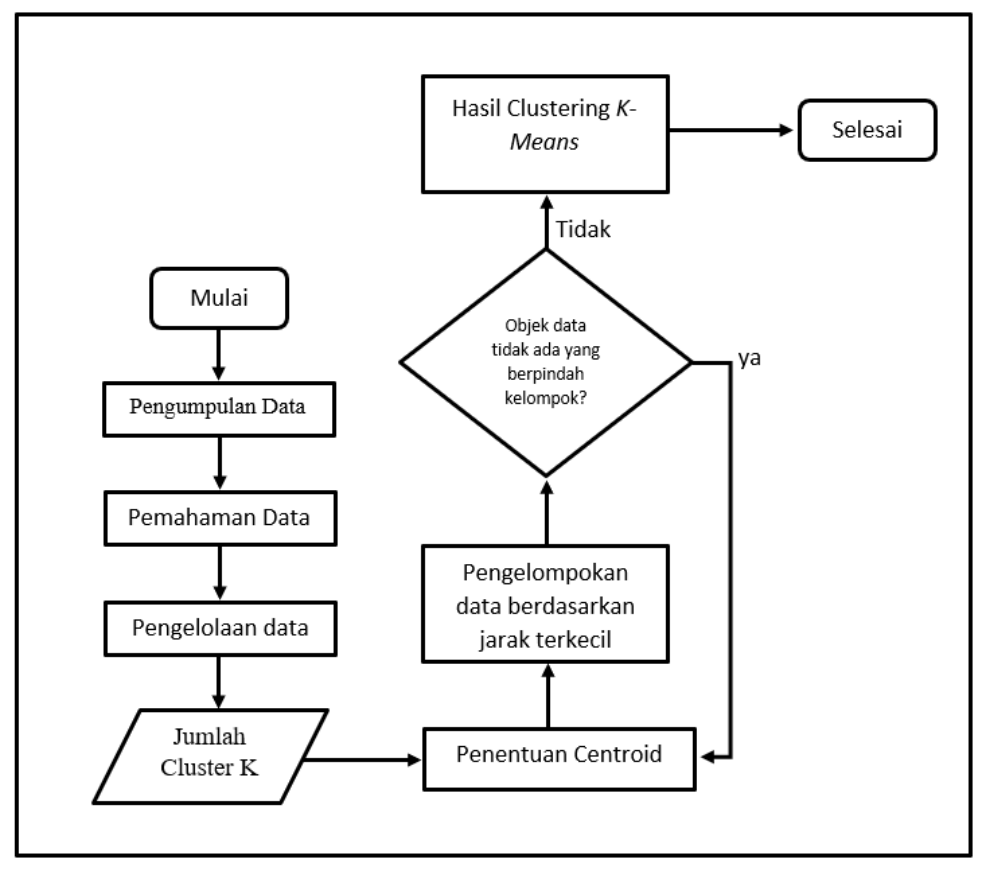

Gambar 2 : Flowchart Penelitian 
Pada gambar 2 penelitian dilakukan dengan Pengumpulan data, dimana pada penelitian ini data yang dipakai merupakan data kuantitatif dengan tipe data disket yang merupakan tipe data berupa angka dan juga bisa berbentuk kategoris beserta atribut atributnya memiliki nilai yang terbatas atau tak terhingga (Arhami \& Nasir, 2020). Objek penelitian yang digunakan adalah data kegiatan ASR bulan maret 2021 yang diambil dari PT Pupuk Kujang Cikampek, Departemen Pemasaran dan Penjualan Ritel. Selanjutnya adalah tahapan pemahaman data, di tahapan ini data dengan atributnya dideskirpsikan agar peneliti mengetahui penjelasanpenjelasan dari tiap tiap atribut. Selanjutnya adalah pengolahan data dimana data disiapkan agar mudah dan siap dalam proses data mining. Setelah data diolah selanjutnya data ditentukan nilai clusternya penentuan cluster ini berdasarkan penelitian yang akan dilakukan dan akan dibentuk beberapa kelompok, setelah peneliti menentukan nilai clusternya maka peneliti mencari nilai centroid. Nilai centroid ini diperoleh dengan cara ser random dan set initial centroid ( Fitria et al, 2020), setelah didapatkan nilai centroid, jika nilai centroid masih berubah maka perlu dilakukan pemilihan titi centroid kembali secara acak dan jika tidak lagi berubah maka tahapan selanjutnya adalah mengelompokan data berdasarkan jarak terkecil dari hasil penentuan nilai centroid. Selanjutnya data yang sudah menjadi beberapa cluster didapatkan hasil berupa evaluasi dari algoritma k-means yang selanjutnya dapat dijadikan suatu ilmu pengetahuan yang berguna bagi perusahaan.

Clustering merupakan salah satu metode pembelajaran tidak terawasi, data dan nilai-nilai yang ada belum mempunyai target atau mempunyai label kelasnya, sehingga perlu diprediksi ke dalam kelas mana nantinya suatu objek itu akan masuk berdasarkan kesamaan polanya atau kesamaan kelompoknya. Pada algoritma K-means ada beberapa langkah yang harus diselesaikan, yaitu (Hendramawan, 2020) :

1. Tentukan nilai $\mathrm{k}$ klaster sesuai dengan yang diinginkan.

2. Pilih titik centroid secara acak.

3. Mengelompokan data sampai terbentuk $\mathrm{K}$ buah cluster dengan titik centroid dari setiap cluster

$$
\mathrm{d}(\mathrm{x}, \mathrm{y})=\sum_{i=1}^{n}(\mathrm{xi}-y i)^{2}
$$

$\mathrm{d}(\mathrm{x}, \mathrm{y})$ adalah jarak antara $\mathrm{x}$ ke data $\mathrm{y}$

xi adalah data testing ke-i

yi adalah data testing ke-1 
4. Perbarui nilai titik centroid

$$
\mu k=\frac{1}{N k} \sum_{i=1}^{n} \mathrm{xi}
$$

$\mu k$ adalah titik centroid dari cluster ke-K

Nk adalah banyaknya data pada cluster ke-k

$\mathrm{Xi}$ adalah data ke-i pada cluster ke-K

5. Mengulang langkah 2 sampai dengan 4 sampai nilai dari titik centroid tidak lagi berubah.

\section{HASIL DAN PEMBAHASAN}

Data kegiatan ASR yang akan dilakukan proses data mining memiliki 4 atribut, yaitu ID ASR, Jumlah Hari Kegiatan, Jumlah Kegiatan, Jenis Kelamin. Penelitian ini akan dilakukan untuk mengevaluasi Kinerja Assistant Sales Representative pada PT Pupuk Kujang Cikampek, Departemen Pemasaran dan Penjualan Ritel dengan mengelompokan menjadi 3 kelompok yaitu kelompok produktif, menengah produktif dan kurang produktif pada dataset kegiatan ASR seperti pada tabel 1.

Tabel 1. Data Kegiatan ASR maret 2021

\begin{tabular}{cccc}
\hline ID ASR & $\begin{array}{c}\text { JUMLAH HARI } \\
\text { KEGIATAN }\end{array}$ & $\begin{array}{c}\text { JUMLAH } \\
\text { KEGIATAN }\end{array}$ & $\begin{array}{c}\text { JENIS } \\
\text { KELAMIN }\end{array}$ \\
\hline 19 & 26 & 122 & 1 \\
\hline 18 & 20 & 84 & 1 \\
\hline 20 & 23 & 110 & 1 \\
\hline 21 & 17 & 66 & 1 \\
\hline 22 & 22 & 98 & 1 \\
\hline 23 & 21 & 102 & 1 \\
\hline 24 & 23 & 103 & 1 \\
\hline 25 & 23 & 104 & 1 \\
\hline 26 & 19 & 97 & \\
\hline 28 & 21 & & \\
\hline & & & 13 \\
\hline
\end{tabular}




\begin{tabular}{|c|c|c|c|}
\hline 31 & 22 & 101 & 1 \\
\hline 32 & 22 & 95 & 1 \\
\hline 34 & 25 & 131 & 1 \\
\hline 35 & 22 & 140 & 1 \\
\hline 37 & 20 & 139 & 1 \\
\hline 39 & 22 & 109 & 1 \\
\hline 40 & 21 & 102 & 1 \\
\hline 41 & 23 & 134 & 1 \\
\hline 42 & 26 & 110 & 1 \\
\hline 43 & 21 & 84 & 1 \\
\hline 44 & 21 & 99 & 1 \\
\hline 45 & 23 & 105 & 1 \\
\hline 46 & 21 & 204 & 1 \\
\hline 47 & 21 & 128 & 1 \\
\hline 48 & 20 & 103 & 1 \\
\hline 49 & 6 & 26 & 1 \\
\hline 50 & 16 & 91 & 1 \\
\hline 51 & 22 & 101 & 1 \\
\hline 52 & 21 & 101 & 1 \\
\hline 53 & 20 & 67 & 1 \\
\hline 54 & 22 & 122 & 1 \\
\hline 55 & 22 & 147 & 1 \\
\hline 56 & 17 & 177 & 1 \\
\hline 58 & 22 & 112 & 1 \\
\hline 59 & 21 & 117 & 1 \\
\hline 65 & 22 & 113 & 1 \\
\hline
\end{tabular}

Parameter utama pada pengelompokan kinerja ASR ini berdasarkan pada dua atribut utama, yaitu atribut jumlah hari kegiatan dan hari kegiatan, lalu ditambah dengan 2 
parameter tambahan yaitu atribut ID ASR, dan Jenis Kelamin. Pengelompokan data berdasarkan 4 atribut tersebut dijelaskan dalam tabel 2.

Tabel 2. Penjelasan detail Atribut

\begin{tabular}{lllll}
\hline Nama Atribut & \multicolumn{3}{c}{ Penjelasan Atribut } & Tipe data \\
\hline ID ASR & Merupakan ID data atau kode identitas ASR & \\
& (Assistant Sales Representative) & & ID \\
\hline Jumlah & Hari & Merupakan banyaknya capaian & kunjungan & dalam \\
Kegiatan & waktu 1 bulan & & Integer \\
\hline Jumlah & Merupakan banyaknya jenis & kunjungan & yang & \\
Kegiatan & dilakukan selama 1 bulan & & Integer \\
\hline Jenis Kelamin & Merupakan identitas ASR, 1 (Pria) 2 (Wanita) & Integer \\
\hline
\end{tabular}

Selanjutnya dari dataset kegiatan ASR pada tabel 1 akan di bagi menjadi 3 kelompok/cluster sehingga nilai K pada perhitungan ini sebesar 3 .

\section{Titik Centroid}

Titik Centroid yang didapatkan pada penelitian ini terbentuk dari 3 klaster dengan masing masing nilai pada tiap atribut seperti pada tabel 3 .

Tabel 3. Titik tengah dari 3 Cluster

\begin{tabular}{llll}
\hline \multicolumn{1}{c}{ Atribut } & Cluster & Cluster & Cluster \\
& $\mathbf{1}$ & $\mathbf{2}$ & $\mathbf{3}$ \\
\hline Jumlah Hari Kegiatan & 17.157 & 21.909 & 21.375 \\
\hline Jumlah Kegiatan & 66.667 & 105.318 & 150 \\
\hline Jenis Kelamin & 1 & 1 & 1
\end{tabular}

Setelah didapatkan nilai titik centroid yang tidak berubah-ubah, langkah selanjutnya adalah mengklaster atau mengelompokan data berdasarkan tiga kelompok, yaitu kelompok produktif, kelompok menengah produktif, dan kelompok kurang produktif dengan hasil seperti pada tabel 4.

Tabel 4. Cluster yang terbentuk

\begin{tabular}{ccccccc}
\hline No & $\begin{array}{c}\text { ID } \\
\text { ASR }\end{array}$ & Cluster & Jenis Cluster & $\begin{array}{c}\text { Jumlah } \\
\text { Harian } \\
\text { Kegiatan }\end{array}$ & $\begin{array}{c}\text { Jumlah } \\
\text { Kegiatan }\end{array}$ & $\begin{array}{c}\text { Jenis } \\
\text { Kelamin }\end{array}$ \\
\hline 1 & 19 & cluster 2 & MENENGAH PRODUKTIF & 26 & 122 & 1 \\
\hline 2 & 18 & cluster 1 & KURANG PRODUKTIF & 20 & 84 & 1 \\
\hline 3 & 20 & cluster 2 & MENENGAH PRODUKTIF & 23 & 110 & 1 \\
\hline 4 & 21 & cluster 1 & KURANG PRODUKTIF & 17 & 66 & 1 \\
\hline 5 & 22 & cluster 2 & MENENGAH PRODUKTIF & 22 & 98 & 1 \\
\hline 6 & 23 & cluster 2 & MENENGAH PRODUKTIF & 21 & 102 & 1
\end{tabular}




\begin{tabular}{|c|c|c|c|c|c|c|}
\hline 7 & 24 & cluster 2 & MENENGAH PRODUKTIF & 23 & 103 & 1 \\
\hline 8 & 25 & cluster 2 & MENENGAH PRODUKTIF & 23 & 104 & 1 \\
\hline 9 & 26 & cluster 1 & KURANG PRODUKTIF & 19 & 73 & 1 \\
\hline 10 & 28 & cluster 2 & MENENGAH PRODUKTIF & 21 & 97 & 1 \\
\hline 11 & 31 & cluster 2 & MENENGAH PRODUKTIF & 22 & 101 & 1 \\
\hline 12 & 32 & cluster 2 & MENENGAH PRODUKTIF & 22 & 95 & 1 \\
\hline 13 & 34 & cluster 3 & PRODUKTIF & 25 & 131 & 1 \\
\hline 14 & 35 & cluster 3 & PRODUKTIF & 22 & 140 & 1 \\
\hline 15 & 37 & cluster 3 & PRODUKTIF & 20 & 139 & 1 \\
\hline 16 & 39 & cluster 2 & MENENGAH PRODUKTIF & 22 & 109 & 1 \\
\hline 17 & 40 & cluster 2 & MENENGAH PRODUKTIF & 21 & 102 & 1 \\
\hline 18 & 41 & cluster 3 & PRODUKTIF & 23 & 134 & 1 \\
\hline 19 & 42 & cluster 2 & MENENGAH PRODUKTIF & 26 & 110 & 1 \\
\hline 20 & 43 & cluster 1 & KURANG PRODUKTIF & 21 & 84 & 1 \\
\hline 21 & 44 & cluster 2 & MENENGAH PRODUKTIF & 21 & 99 & 1 \\
\hline 22 & 45 & cluster 2 & MENENGAH PRODUKTIF & 23 & 105 & 1 \\
\hline 23 & 46 & cluster 3 & PRODUKTIF & 21 & 204 & 1 \\
\hline 24 & 47 & cluster 3 & PRODUKTIF & 21 & 128 & 1 \\
\hline 25 & 48 & cluster 2 & MENENGAH PRODUKTIF & 20 & 103 & 1 \\
\hline 26 & 49 & cluster 1 & KURANG PRODUKTIF & 6 & 26 & 1 \\
\hline 27 & 50 & cluster 2 & MENENGAH PRODUKTIF & 16 & 91 & 1 \\
\hline 28 & 51 & cluster 2 & MENENGAH PRODUKTIF & 22 & 101 & 1 \\
\hline 29 & 52 & cluster 2 & MENENGAH PRODUKTIF & 21 & 101 & 1 \\
\hline 30 & 53 & cluster 1 & KURANG PRODUKTIF & 20 & 67 & 1 \\
\hline 31 & 54 & cluster 2 & MENENGAH PRODUKTIF & 22 & 122 & 1 \\
\hline 32 & 55 & cluster 3 & PRODUKTIF & 22 & 147 & 1 \\
\hline 33 & 56 & cluster 3 & PRODUKTIF & 17 & 177 & 1 \\
\hline 34 & 58 & cluster 2 & MENENGAH PRODUKTIF & 22 & 112 & 1 \\
\hline 35 & 59 & cluster 2 & MENENGAH PRODUKTIF & 21 & 117 & 1 \\
\hline 36 & 65 & cluster 2 & MENENGAH PRODUKTIF & 22 & 113 & 1 \\
\hline
\end{tabular}

Pada tabel 4 didapatkan sebanyak 6 ASR masuk kedalam kelompok klaster 1 yaitu kelompok kurang produktif, lalu sebanyak 22 ASR masuk kedalam kelompok klaster 2 yaitu kelompok menengah produktif dan selanjutnya sebanyak 8 ASR masuk kedalam kelompok klaster 3 yaitu kelompok produktif.

\section{SIMPULAN}

Berdasarkan penelitian yang sudah dilakukan, maka dapat diambil sebuah kesimpulan berupa informasi dan pengetahuan. Didapatkan nilai centroid pada cluster ke-1 memiliki nilai paling kecil untuk semua atribut utama (Jumlah Hari Kegiatan $=17.157$, Jumlah Kegiatan $=66.667)$ dibandingkan dengan cluster ke- 2 dan ke-3. Cluster ke-1 yaitu kelompok kurang produktif yang selanjutnya para ASR yang masuk kedalam kelompok ini sebanyak 6 ASR dapat dilakukan evaluasi dan dilakukan pelatihan agar kedepannya PT Pupuk Kujang 
Cikampek, Departemen Pemasaran dan Penjualan Ritel dapat menyelesaikan permasalahan target yang akan dicapai oleh para ASR menjadi lebih baik.

Hasil analisa capaian evaluasi target ASR dengan bantuan data mining menggunakan metode clustering teknik algoritma K-Means dapat membantu dalam pemberian informasi dan pengetahuan yang sebelumnya belum terbentuk dengan adanya hasil analisa pada penelitian ini PT Pupuk Kujang Cikampek, Departemen Pemasaran dan Penjualan Ritel menjadi lebih mudah dan efisien dalam mengatur strategi dalam mengevaluasi kinerja ASR.

\section{REFERENSI}

Alinse, R. T., Sari, V. N., \& Sallaby, A. F. (2021). MENENTUKAN POLA PEGAWAI HONORER DI DINAS PERUMAHAN KAWASAN PEMUKIMAN DAN PERTANAHAN DALAM PENERAPAN METODE K-MEANS. JURNAL MEDIA INFOTAMA, 17(1).

Oktiani, N., Utami, C. P., \& Yuliantari, K. (2019). Pendekatan Clustering Budaya Organisasi dalam Upaya Peningkatan Kinerja Karyawan. JKBM (JURNAL KONSEP BISNIS DAN MANAJEMEN), 6(1), 33-44.)

Purba, W., \& Siawin, W. (2019). Implementasi Data Mining Untuk Pengelompokkan Dan Prediksi Karyawan Yang Berpotensi Phk Dengan Algoritma K-Means Clustering. Jurnal Sistem Informasi dan Ilmu Komputer Prima (JUSIKOM PRIMA), 2(2), 85-90.).

Suntoro, J. (2019). Data Mining: Algoritma dan Implementasi dengan Pemrograman PHP. Elex Media Komputindo.

Arhami, M., Kom, M., \& Muhammad Nasir, S. T. (2020). Data Mining-Algoritma dan Implementasi. Penerbit Andi.

Vulandari, R. T. (2017). Data Mining: Teori dan Aplikasi Rapidminer.

Bahauddin, A., Fatmawati, A., \& Sari, F. P. (2021). Analisis Clustering Provinsi di Indonesia Berdasarkan Tingkat Kemiskinan Menggunakan Algoritma K-Means. Jurnal Manajemen Informatika Dan Sistem Informasi, 4(1), 1-8.

HENDRAWAN, A. Y. (2020). PENINGKATAN KINERJA ALGORITMA K MEANS DENGAN MENGGUNAKAN PARTICLE SWARM OPTIMIZATION DALAM PENGELOMPOKAN DATA PENYEDIAAN AKSES. Electro Luceat, 6(2), 213-227. 
Marpaung, P., \& Siahaan, R. F. (2021). Penerapan Algoritma K-Means Clustering Untuk

Pemetaan Kepadatan Penduduk Berdasarkan Jumlah Penduduk Kota Medan. J-SAKTI (Jurnal Sains Komputer dan Informatika), 5(1), 503-521.

Fitria, L., Amir, F., \& Bahri, R. (2020). SMART TRASH MENGGUNAKAN METODE CLUSTERING DENGAN PENDEKATAN CENTROID LINKAGE. Jurnal Teknologi, 12(2), 159-166. 